\title{
KAJIAN EPIDEMIOLOGI MANAJERIAL PETUGAS SURVEILANS PUSKESMAS YANG BERPENGARUH TERHADAP PELAKSANAAN PENANGGULANGAN LEPTOSPIROSIS (Studi Di Kota Yogyakarta)
}

\author{
Juli Widiyanto Hendro Basuki \\ Dosen D III Keperawatan Universitas Muhammadiyah Riau \\ Sie Surveilans Dinas Kesehatan Kota Yogyakarta
}

\begin{abstract}
ABSTRAK
Latar Belakang: Leptospirosis merupakan salah satu penyakit penular yang seringkali menimbulkan kejadian luar biasa (KLB), untuk mengurangi kasus penyakit leptospirosis diperlukan upaya kewaspadaan dini. Sistem manajerial yang baik dalam hal ini adalah kelengkapan dan ketepatan laporan minguan W2 sebagai salah satu upaya kewaspadaan dini terutama pada pelaksana penanggulangan yaitu petugas surveilans puskesmas dapat mendukung keberhasilan program penanggulangan kejadian akibat leptospirosis. Penelitian ini bertujuan untuk mengetahui pelaksanaan aspek manajerial pada petugas surveilans puskesmas.Metode: Penelitian ini merupakan penelitian observasional dengan pendekatan cross-sectional. Populasi target dan populasi studi adalah semua petugas surveilans puskesmas di Kota Yogyakarta. Pengumpulan data menggunakan kuesioner dan wawancara mendalam. Data di analisis dengan uji chi-square.Hasil: Hasil penelitian menunjukan bahwa aspek perencanaan dan aspek pelaksanaan terbukti tidak berhubungan sementara aspek pengawasan, monitoring dan evaluasi terbukti berhubungan dengan kelengkapan dan ketepatan laporan mingguan W2 dalam keberhasilan penanggulangan leptospirosis di Kota Yogyakarta ( $\mathrm{PR}=3,33 ; \mathrm{p}=0,002)$

Simpulan: Berdasar kondisi tersebut disimpulkan bahwa aspek pengawasan, monitoring dan evaluasi merupakan aspek manajerial yang berhubungan dengan kelengkapan dan ketepatan laporan mingguan W2 dalam keberhasilan program penanggulangan leptospirosis di Kota Yogyakarta. Disarankan agar faktor pengawasan, monitoring dan evaluasi senantiasa dilakukan secara terpadu dan berkelanjutan. Bagi petugas surveilans puskesmas disarankan untuk meningkatkan kemampuan, kedisiplinan dalam pengaturan jadual dan bekerjasama dengan pemegang program lainnya.
\end{abstract}

Kata kunci: manajerial, leptospirosis, petugas surveilans puskesmas

\section{PENDAHULUAN}

Leptospirosis merupakan penyakit menular yang masih sering menimbulkan kejadian luar biasa dan tidak jarang menyebabkan kematian. Penyakit bersumber binatang (zoonosis) ini disebabkan oleh mikroorganisme berbentuk spiral dan bergerak aktif yang disebut leptospira Penyakit ini dikenal dengan berbagai nama seperti Mud fever, Slime fever (Shlamn fieber), Swam fever, Autumnal fever, Infectious jaundice, Field fever, Cane cutter dan lain-lain(1) Gejala klinik yang timbul mulai dari ringan sampai berat bahkan menimbulkan kematian bila terlambat mendapat pengobatan(2) Berdasarkan berat ringannya gejala klinik, leptospirosis dibagi menjadi 2 jenis yaitu leptospirosis ringan (leptospirosis tanpa ikterik) dan leptospirosis berat (leptospirosis dengan ikterik) (2-4)

Leptospirosis yang sering dijumpai adalah bentuk yang ringan (85-90\% kasus), dimana gejala yang timbul itu tidak khas, yang meliputi sakit kepala, demam, myalgia (flu- 
like illness), keluhan gastrointestinal, manifestasi hemoragik ringan, seperti suffusi konjungtiva, sehingga biasanya pasien tidak terlalu mendapat perhatian medik.(2, 4-5) Pada leptospirosis yang berat (5-10\% kasus), gejala yang timbul selain ikterus bisa ditemukan pneumonia, perdarahan, meningitis maupun gagal ginjal $(4,6)$

Di Indonesia, leptospirosis merupakan penyakit yang selalu ada (emerging desease), sering ditemukan di DKI Jakarta, Jawa Barat, Jawa Timur, DI Yogyakarta, Lampung, Sumatera Selatan, Utara, Bali, NTB, Sulawesi Selatan, Kalimantan Timur dan Kalimantan Barat. Leptospirosis seringkali luput dari diagnosis karaena gejala klinis tidak spesifik dan sulit dilakukan konfirmasi diagnosis tanpa uji laboratorium (7)

Di Propinsi Daerah Istimewa Yogyakarta pada tahun 2011 ditemukan 626 kasus Leptospirosis dengan angka kematian (CFR) sebesar $6,87 \%$ yang tersebar di seluruh kabupaten/kota. Data yang diperoleh dari Dinas Kesehatan Provinsi DIY menunjukkan bahwa CFR yang tertinggi terjadi di Kota Yogyakarta. Dari 38 penderita yang ditemukan tahun 2011, 7 penderita di antaranya meninggal dunia, yang berarti CFR-nya sebesar 18,42 \%, Hasil penyelidikan epidemiologi menunjukkan bahwa tidak satupun dari 38 penderita tersebut ditemukan oleh puskesmas sehingga memberikan asumsi ketidaksiapan puskesmas dan masyarakat dalam mendeteksi kasus leptospirosis.

Leptospirosis erat kaitannya dengan perilaku kebersihan individu (personal hygiene) dan sanitasi lingkungan sebagai faktor risiko. Dalam pengendalian penyakit leptospirosis juga harus memperhatikan faktor lain yaitu managerial yang peranannya sangat menentukan terutama dalam pelaksanaan program pengendalian penyakit menular khususnya leptospirosis, mengingat manajemen merupakan suatu proses kegiatan yang meliputi perencanaan, pelaksanaan, dan pengawasan, monitoring dan evaluasi untuk mencapai tujuan organisasi yang telah ditetapkan.

Dinas Kesehatan Kota Yogyakarta merupakan salah satu unsur pelaksana teknis Pemerintah Daerah Kota Yogyakarta yang bertanggung jawab terhadap pembangunan bidang kesehatan dalam meningkatkan derajat manusia memiliki 18 puskesmas dan 12 puskesmas pembantu, dimana setiap puskesmas terdapat seorang Petugas Surveilan yang bertanggung jawab terhadap semua peristiwa yang berkaitan dengan penyakit menular termasuk leptospirosis. Dalam berbagai keterbatasannya, Petugas Surveilans harus melaksanakan Surveilans Epidemiologi agar dapat dilakukan penanggulangan yang efektif dan efisien terhadap masalah kesehatan masyarakat tersebut. Pembinaan terhadap petugas surveilans puskesmas sudah dilakukan melalui pertemuan koordinasi, dengan memberikan umpan balik / feedback dan sekaligus dilakukan valiasi data.

Pembinaan juga melalui penyegaran program dengan mengadakan pelatihan yang berkaitan dengan surveilans baik tentang penyakit menular ataupun tidak menular. Dalam rangkaian kegiatan tersebut sangat diperlukan suatu perencanaan dan pelaksanaan yang tepat sehingga pada pelaksanaan penanggulangannya dapat lancar dan terarah. Monitoring dan evaluasi yang terpadu diperlukan agar kesalahan yang pernah terjadi tidak terulang kembali yang pada akhirnya dapat menurunkan angka kesakitan ataupun angka kematian secara bermakna.

\section{METODOLOGI PENELITIAN}

Penelitian kajian epidemiologi manajerial pelaksanaan penanggulangan leptospirosis ini 
merupakan penelitian epidemiologi observasional dengan pendekatan Crosssectional dimana pengukuran variabel bebas dan variabel terikat dilakukan hanya satu kali pada satu saat, artinya tidak ada follow-up atau tidak ada prosedur tindak lanjut. Ukuran epidemiologi yang digunakan adalah rasio prevalens, yang dihitung dengan membagi prevalens efek pada kelompok dengan faktor risiko dengan prevalens efek pada kelompok tanpa faktor risiko.(8)

Penelitian ini dilaksanakan di Kota Yogyakarta pada bulan Mei - Juli 2012. Populasi studi pada penelitian ini adalah semua Petugas Surveilans Puskesmas di Kota Yogyakarta

Sampel pada penelitian ini petugas surveilans puskesmas yang berjumlah 18 orang dari 18 puskesmas, artinya bahwa semua petugas pemegang program surveilans puskesmas diambil atau dijadikan sebagai sampel atau biasa disebut total sampling atau sampel jenuh. Sampling jenuh adalah teknik penentuan sampel yang digunakan jika semua anggota populasi menjadi sampel. Pada umumnya sampel penelitian seperti ini dilakukan apabila mempunyai jumlah sampel yang relatif kecil, kurang dari 30 orang.(9)

Variabel bebas penelitian ini adalah aspek manajerial pada tahapan perencanaan, tahapan pelaksanaan serta tahapan pengawasan, monitoring dan evaluasi. Sedangkan variabel terikat dalam penelitian ini adalah keberhasilan program pelaksanaan penanggulangan leptospirosis di Kota Yogyakarta, di dalam sudut pandang manajerial berupa kelengkapan dan ketepatan laporan mingguan W2. Pengumpulan data dilakukan dengan menggunakan kuesioner, observasi data laporan dan indepth interview pada Petugas Surveilans Puskesmas dan Kepala Puskesmas.

Pengolahan dan analisis data pada penelitian ini dilakukan menggunakan alat bantu komputer dengan program SPSS for windows release 13.0. Data yang terkumpul diolah secara univariat untuk melihat deskripsi dari karakteristik responden dan dari setiap variabel. Pengolahann secara bivariat melalui analisis Prevalensi Rasio (PR) dengan uji Chi square menggunakan tabel 2x2 untuk mengetahui faktor risiko yang mempengaruhi variabel terikat (10).

\section{HASIL DAN PEMBAHASAN}

Kota Yogyakarta mempunyai luas wilayah 32,50 $\mathrm{Km}^{2}$ dengan pembagian wilayah menjadi 14 kecamatan, 45 kelurahan, 616 rukun warga dan 2.522 rukun tetangga. Kepadatan penduduk Kota Yogyakarta $14.086 \mathrm{jiwa} / \mathrm{km} 2$, sedangkan rasio penduduk laki-laki dan perempuan 1: 0,9907. Laju pertumbuhan penduduk Kota Yogyakarta rata-rata $1,12 \%$ per tahun (BPS Kota Yogyakarta). Jumlah Penduduk Kota tahun 2010 sebesar 447.143 jiwa dengan proporsi jumlah penduduk menurut jenis kelamin lakilaki 217.378 dan perempuan 229.765

Dinas Kesehatan sebagai salah satu Unit Pelaksana Teknis (UPT) Pemerintah Daerah Kota Yogyakarta membawahi 18 puskesmas, 11 puskesmas pembantu dan 18 puskesmas keliling. Petugas surveilans puskesmas merupakan salah satu dari petugas puskesmas yang melakukan pelayanan kepada masyarakat khususnya di bidang penanggulangan penyakit menular, termasuk leptospirosis, dimana setiap puskesmas hanya memiliki 1 orang petugas surveilans.

Distribusi umur petugas surveilans puskesmas antara 25 - 52 tahun dan rerata adalah 42 tahun. Masa kerja petugas surveilans puskesmas antara $3-24$ tahun, sementara lamanya sebagai pemegang program surveilans puskesmas antara $1-15$ tahun dan reratanya adalah 5 tahun. Dari 18 petugas surveilans puskesmas sebagian besar berjenis kelamin perempuan yaitu sebanyak 
16 orang $(88,89 \%)$. Tingkat pendidikan petugas surveilans puskesmas sudah cukup memadai, $50 \%$ sudah menempuh tingkat S1/D-IV, 27,78 \% berpendidikan D-III dan hanya 22,22 \% saja yang berpendidikan SMA.

Salah satu indikator keberhasilan penanggulangan leptospirosis dengan melaksanakan kegiatan kewaspadaan dini yaitu terselenggaranya sistem pelaporan yang lengkap dan tepat. Laporan Mingguan Wabah ( W2 ) adalah salah satu laporan yang harus dilaksanakan oleh petugas surveilans puskesmas. Dari 18 puskesmas masih terdapat 8 puskesmas $(44,44 \%)$ yang belum melaksanakan pelaporan secara lengkap dan tepat. Secara keseluruhan laporan mingguan wabah (W2) yang lengkap dan tepat baru 80 $\%$. Hal ini dapat terlihat jelas pada table berikut.

Tabel 1: Absensi Laporan Mingguan Wabah ( W2 ) per Puskesmas Tahun 2011

\begin{tabular}{|c|c|c|c|c|c|}
\hline \multirow{2}{*}{$\frac{\mathrm{NO}}{1}$} & PUSKESMAS & $\begin{array}{c}\text { JENIS } \\
\text { LAPORAN }\end{array}$ & JML & $\%$ & $\begin{array}{c}\% \\
\text { KELENGKAPAN/KETEPATAN }\end{array}$ \\
\hline & Pakualaman & $\begin{array}{l}\text { Kelengkapan } \\
\text { Ketepatan }\end{array}$ & $\begin{array}{l}52 \\
51\end{array}$ & $\begin{array}{c}100 \\
98\end{array}$ & 99 \\
\hline 2 & Ngampilan & Kelengkapan & 43 & 83 & 54 \\
\hline & & Kelengkapan & 51 & 98 & \\
\hline 3 & & Ketepatan & 28 & 54 & \\
\hline 4 & Kotagede I & Kelengkapan & 51 & 98 & \\
\hline & & Ketepatan & 52 & 100 & \\
\hline 5 & Kotaoede II & Kelengkapan & 52 & 100 & 92 \\
\hline$J$ & Kotagede II & Ketepatan & 44 & 85 & \\
\hline 6 & Gondokusum & Kelengkapan & 50 & 96 & 71 \\
\hline 0 & 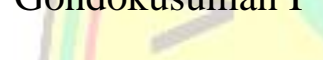 & Ketepatan & 24 & 46 & \\
\hline 7 & Gondokusuman II & Kelengkapan & 51 & 98 & 92 \\
\hline & (1) & Ketepatan & 45 & 87 & \\
\hline 8 & Danurjan I & Kelengkapan & 36 & 69 & 40 \\
\hline & & Ketepatan & $\begin{array}{c}6 \\
51\end{array}$ & $\begin{array}{l}12 \\
98\end{array}$ & \\
\hline 9 & Dan & Ketepatan & 8 & 15 & \\
\hline 10 & Umbulhario I & Kelengkapan & 52 & 100 & \\
\hline 10 & umbuinarjo i & Ketepatan & 50 & 96 & \\
\hline 11 & Umbulhario II & Kelengkapan & 50 & 96 & 94 \\
\hline & & Ketepatan & 48 & 92 & \\
\hline 12 & Gondomanan & Kelengkapan & 51 & 98 & 88 \\
\hline & Gonuontallant & Ketepatan & 40 & 77 & 88 \\
\hline & & Kelengkapan & 52 & 100 & \\
\hline 13 & Mantrıjeron & Ketepatan & 38 & 73 & 87 \\
\hline & & Kelengkapan & 52 & 100 & \\
\hline 14 & Wirobrajan & Ketepatan & 7 & 13 & 57 \\
\hline 15 & Gedonotenoen & Kelengkapan & 41 & 79 & 72 \\
\hline 15 & Uedonglengen & Ketepatan & 34 & 65 & 12 \\
\hline 16 & Kraton & Kelengkapan & 52 & 100 & \\
\hline 10 & Kraton & Ketepatan & 22 & 42 & 71 \\
\hline 17 & Jetis & Kelengkapan & 52 & 100 & 04 \\
\hline 17 & Jetis & Ketepatan & 46 & 88 & 94 \\
\hline 18 & Tegarejo & Kelengkapan & 52 & 100 & 97 \\
\hline
\end{tabular}




\begin{tabular}{|c|c|c|c|c|c|}
\hline NO & PUSKESMAS & $\begin{array}{c}\text { JENIS } \\
\text { LAPORAN }\end{array}$ & JML & $\%$ & $\begin{array}{c}\% \\
\text { KELENGKAPAN/KETEPATAN }\end{array}$ \\
\hline & & Ketepatan & 49 & 94 & \\
\hline & Total & $\begin{array}{l}\text { Kelengkapan } \\
\text { Ketepatan }\end{array}$ & $\begin{array}{l}892 \\
604\end{array}$ & $\begin{array}{l}95 \\
65\end{array}$ & 80 \\
\hline
\end{tabular}

\section{Analisis bivariat.}

Anlisis bivariat menggunakan Analisa Prevalensi Ratio (PR) dengan uji Chi Square digunakan untuk mengetahui faktor yang mempengaruhi dari aspek manajerial petugas surveilans puskesmas terhadap kengkapan dan ketepatan laporan mingguan W2 dalam keberhasilan program penanggulangan leptospirosis.

Tabel 2: Analisis Bivariat Aspek Manajerial Petugas Surveilans Puskesmas terhadap Keberhasilan Pelaksanaan Penanggulangan Leptospirosis di Kota Yogyakarta

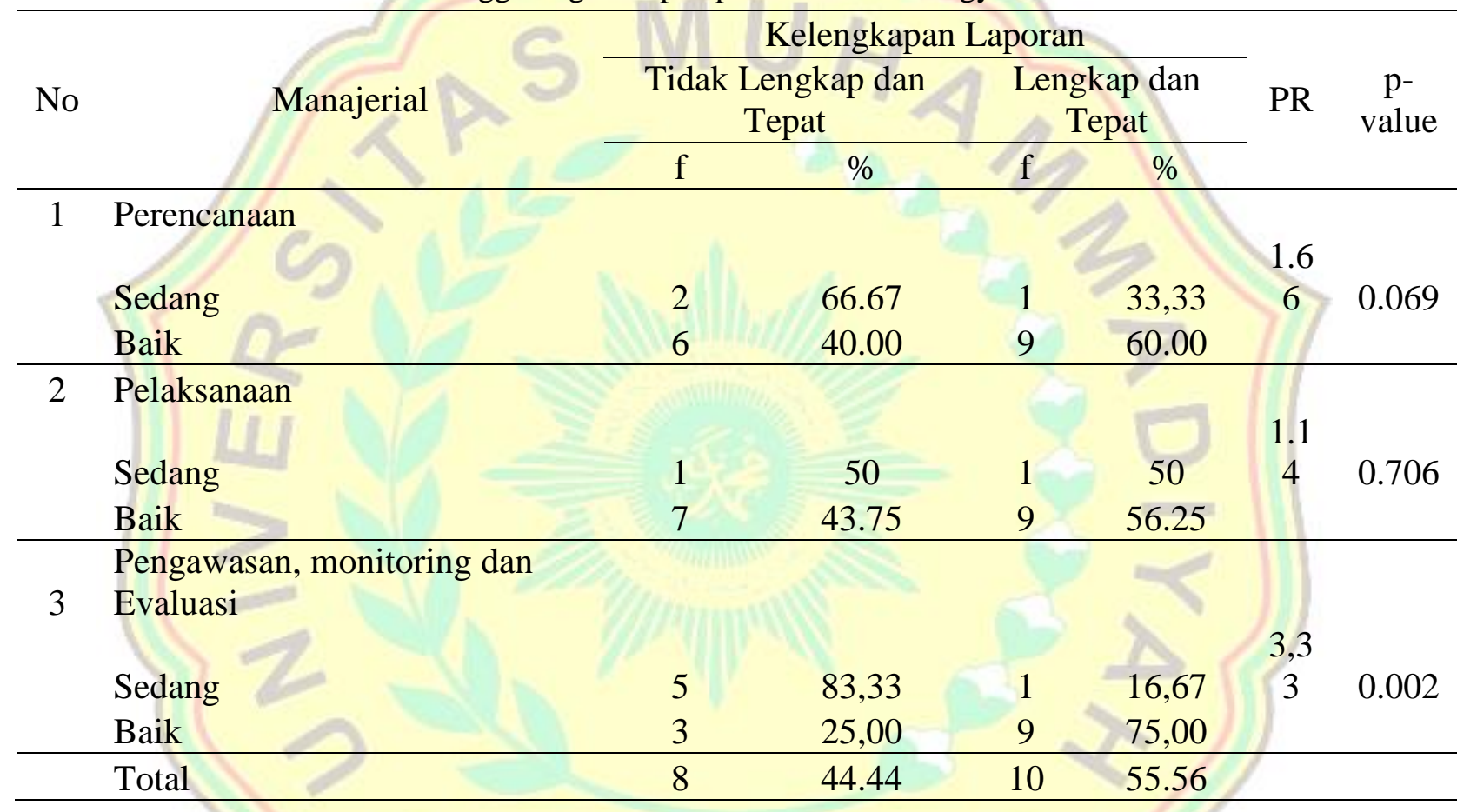

Dari tabel terlihat bahwa aspek manajerial pada tahapan perencanaan tidak berpengaruh terhadap kelengkapan dan ketepatan laporan mingguan W2 dalam keberhasilan program penanggulangan leptospirosis, demikian juga aspek manajerial pada tahapan pelaksanaan dengan ditunjukan nilai p-value berturut turut 0,069 dan 0,706 Sedang aspek manajerial pada tahapan pengawasan, monitoring dan evaluasi berpengaruh terhadap kelengkapan dan ketepatan laporan mingguan W2 dalam keberhasilan program penanggulangan leptospirosis yang ditunjukan nilai PR 3,33 dan p-value 0,002 .
Penanggulangan leptospirosis harus dilakukan dengan komperehensif dan menyeluruh baik dari lingkungan maupun dari manusianya sendiri, juga secara fisik yaitu penanganan terhadap vektor penularnya dan yang tidak bisa diabaikan adalah dari sisi manajerial. Integritas program merupakan hal yang penting dan diperlukan untuk mendasari program penanggulangan tersebut, dimana integritas itu terdiri dari standar dan kebijakan pemerintah, transparasi, akuntabilitas, partisipasi aktif dan etika profesional. 
Hasil penelitian menunjukan bahwa pada tahapan perencanaan terbukti tidak berpengaruh terhadap kelengkapan dan ketepatan laporan mingguan W2 dalam keberhasilan program penanggulangan leptospirosis demikian pula aspek manajerial pada tahap pelaksanaan dengan ditunjukan nilai p-value berturut turut 0,069 dan 0,706 Hal ini dapat terjadi kemungkinan karena ketika petugas surveilans puskemas menyusun perencanaan, berorientasi atau dipandang sebagai suatu kewajiban yang harus dilaksanakan. Selain itu karena kesibukan petugas surveilans puskesmas karena ketugasannya yang merangkap sehingga terkesan dalam pembuatan perencanaan hanya asal jadi.

Penelitian lain senada dengan hasil penelitian ini yang mengemukakan bahwa sukses perencanaan tergantung atas kemampuan dan kecakapan perencana dan di dalam menyusun perencanaan harus memasukan alokasi waktu untuk setiap bagian dari aktifitas, dengan keterbatasan waktu menimbulkan perencanaan kurang optimum(11)

Perencanaan sebagai suatu proses yang berorientasi masa depan secara sistematis menentukan arah, menentukan sebuah sasaran dan tindakan untuk mencapai tujuan. Perencanaan sangat penting untuk semua fungsi manajerial dan merupakan salah satu kegiatan yang paling penting dimana perencanaan bertanggung jawab untuk kegiatan program kesehatan(12) Konsistensi dalam penyusunan perencanaan harus dijaga karena perencanaan adalah proses mempersiapkan serangkaian keputusan untuk tindakan yang akan datang yang digunakan untuk mencapai sasaran dengan cara yang optimal, oleh karena itu proses perencanaan harus terjadi secara terus menerus dalam suatu unit organisasi.(13)
Hasil penelitian pada tahapan pelasanaan juga tidak berpengaruh terhadap kelengkapan dan ketepatan laporan mingguan W2 dalam keberhasilan program penanggulangan leptospirosis. Keterbatasan ketenagaan kemungkinan menjadi penyebabnya dimana rasio 1 sarana kesehatan (puskesmas) dalam hal ini 1 petugas surveilans harus mengampu sebanyak 25.426 penduduk, selain itu kemungkinan karena ketugasan rangkap juga mempengaruhi.

Hasil penelitian menunjukan bahwa pada tahap pengawasan, monitoring dan evaluasi ini terbukti berhubungan terhadap keberhasilan pelaksanaan penanggulangan leptospirosis dengan ditunjukan nilai $\mathrm{p}$-valeu 0,002 dan PR sebesar 3,33. Hal ini terjadi kemungkinan adanya ketentuan dari Dinas Kesehatan Kota Yogyakarta yang mewajibkan bahwa laporan mingguan-W2 harus dilaporkan ke Dinas Kesehatan pada hari Selasa minggu berikutnya

Adanya pengawasan, monitoring dan evaluasi berupa dukungan dari Kepala Puskesmas sangat diperlukan untuk meningkatkan kinerja. Hal ini senada dengan hasil penelitian Sutarman yang menerangkan bahwa tidak ada motivasi dari pimpinan Puskesmas $\mathrm{OR}=7,92(95 \% \mathrm{CI}=1,24-$ $27,97)$ dan tidak ada perhatian dari pimpinan Puskesmas OR=5,95 (95\% CI = 1,77 - 20,02) akan mempengaruhi keterlambatan petugas dalam menyampaikan laporan KLB dari puskesmas ke Dinas Kesehatan.(14)

\section{KESIMPULAN}

Aspek manajerial pada tahapan pengawasan, monitoring dan evaluasi terbukti berpengaruh terhadap kelengkapan dan ketepatan laporan W2 dalam keberhasilan program penanggulangan leptospirosis di Kota Yogyakarta. Peran Dinas Kesehatan Kota Yogyakarta khususnya Bidang Promosi, Pengembangan dan Sistem Informasi 
Kesehatan selaku pembina langsung terhadap petugas surveilans puskesmas sangat besar. Aspek manajerial pada tahapan perencanaan dan tahapan pelaksanaan terbukti tidak berpengaruh terhadap kelengkapan dan ketepatan laporan W2 dalam keberhasilan program penanggulangan leptospirosis. Terdapat 4 puskesmas yang sangat bermasalah dengan sistem pelaporan mingguan W2 dari 18 puskesmas yang ada di Kota Yogyakarta. Sehingga diperlukan peningkatan kapasitas dan kedisiplinan petugas surveilans puskesmas, juga koordinasi dan kerja sama baik dengan Kepala Puskesmas maupun dengan sesama petugas puskesmas. Selain itu perlu meningkatkan ketrampilan dan pengetahuan tentang manajerial dan leptospirosis melalui pelatihan, seminar, termasuk pendidikan baik formal maupun informal.

\section{DAFTAR PUSTAKA}

\section{ASHRAE HANDBOOK, (2005),}

Fundamental American Society of Heating, Refrigeration and Air Conditioning Engineer, SI Edition

WHO. Human Leptospirosis: Guidance For Diagnosis, Surveillance, And Control. 2003.

Jawetz., Melnick, adelberg's. Mikrobiologi Kedokteran. Diterjemahkan Oleh Bagian Mikrobiologi Fakultas Kedokteran Universitas Air Langga. Surabaya: Salemba Medika;. 2001.

P.N L. Leptospirosis. In: Clin. Microbiol. Rev.14(2). 2001.

Muthusethupathi.M.A. Leptospirosis-Is There A Need For Concern ? Http://Wwwcavingorguk/Wdic/Madra s2000 Diakses 17 Desember 2011 [Serial On The Internet]. 2007.

Wagenaar.F.P. GMGA, Sakundarno.M.S., Gasem.M.H., Mairuhu.A.T.A., Hartskeeri.R. What Role Do
Coagulation Disorders Play In The Pathogenesis Of Leptospirosis? Tropical Medicine And International Health. 2007;Jan;12(1):111-22. 2007.

Siswandari. Diagnosis Leptospirosis. Mandala Of Health 2006; Sept; 2(3):33-45. 2006.

Kholis.Ernawati. Leptospirosis Sebagai Penyakit Pasca Banjir Serta Cara Pencegahannya. Widya Kedokteran, Nomor 274,Juli,. 2007.

Hulley SB CS, Browner WS, Grady D, Newman TB. Designing Clinical Research An Epidemiology Approch. 2 Ed. Philadelphia: Lippincott Williams \& Wilkins;. 2007.

Sugiyono. Statistika Untuk Penelitian, CV. Alfabeta, Bandung. 2000.

Petrie A SC. Medical Statisticat A Glance. London: Blackwell Science; 2000.

Ningsih.D. Perencanaan Dalam Pengadaan Barang/Jasa Pemerintah Pada Kantor Wilayah Badan Pertanahan Nasional (BPN) Provinsi Jawa Tengah. Semarang: Universitas Diponegoro; . 2010.

Peddecorn.K.M. "Public Health Management Tools Planning" In Maxcy-RoseuLast: Public Health And Preventive Medicine, 14th Ed., Edited By R.B.Wallace And B.N.Doebbeling, Stamford,CT:Appleton \& Lang. 1998. Quade.B.S. Analysis For Public Desicion, North-Bolland, New York, . 1984.

Sutarman. Faktor-Faktor Yang Berhubungan Dengan Keterlambatan Petugas Dalam Menyampaikan Laporan KLB Dari Puskesmas Ke Dinas Kesehatan Kota Semarang (Studi Di Kota Semarang). Semarang: Diponegoro;. 2008. 